A linguagem dos pássaros: uma epopeia espiritual

Faustino Teixeira*

\title{
Introdução
}

Um dos maiores estudiosos da obra de Farîd ud-dîn Attâr (1158-1221) é, sem dúvida, Helmut Ritter, que escreveu a importante obra, O mar da alma (1955), em torno da visão de homem, mundo e Deus no pensamento do místico persa. ${ }^{1}$ Dentre as diversas obras de Attâr, destacase Mantiq at-Tayr (A linguagem dos pássaros), um grande poema místico no estilo de um matnawî religioso ${ }^{2}$, que aborda uma "épica da alma" em sua busca do Mistério de Deus.

As traduções da Linguagem dos pássaros são normalmente em prosa, ainda que o original persa seja em verso. Temos a tradução francesa de Garcin de Tassy (1982) e a italiana organizada por Carlo Saccone (1999). No Brasil são duas traduções: A conferência dos pássaros (1993) e A linguagem dos pássaros (1991) ${ }^{3}$. Há também o texto teatral, adaptado por Jean-Claude Carrière. ${ }^{4}$ Mais recentemente foi publicada a magnífica tradução francesa de autoria de Leili Anvar, que retoma o original persa em verso. ${ }^{5}$

\section{Uma epopeia do amor}

A linguagem dos pássaros (Mantiq at-Tayr) é a obra clássica de um dos mais prestigiados místicos do sufismo no século XIII, o persa Farid ud-Din Attar. Esta obra veio recentemente enriquecida com a bela tradução realizada por Leili Anvar, diretamente do persa para o francês na editora Diane de Selliers (Paris, 2012) ${ }^{6}$. Sobretudo por recuperar o

*Professor do Programa de Pós-Graduação em Ciência da Religião da Universidade Federal de Juiz de Fora.

${ }^{1}$ Hellmut Ritter. Il mare dell'anima. Uomo, mondo e Dio in Farîduddîn 'Attâr. Milano: Ariele, 2004 (a edição alemã original é de 1955).

2 Para esclarecimentos sobre a forma do mathnavi persa cf. Carlo SACCONE. II maestro sufi e la bella cristiana. Roma: Carocci, 2005, p. 55 e 62.

${ }^{3}$ Farîd ud-Din Attar. Le langage des oiseaux. Paris: Albin Michel, 1996; Id. I/ verbo degli uccelli. Milano: Mondadori, 1999; Id. A conferência dos pássaros. São Paulo: Cultrix, 1993; Id. A linguagem dos pássaros. 2 ed. São Paulo: Attar, 1991.

${ }^{4}$ La conférence des oiseaux. Récit théatral de Jean-Claude Carrière. Paris: Albin Michel, 2008.

${ }^{5}$ Farîd od-dîn 'Attar. Le cantique des oiseaux. Paris: Selliers, 2013.

${ }^{6}$ Em edição seguinte, da mesma editora, a obra veio enriquecida com magníficas ilustrações da pintura no Islã do Oriente: Diane de Selliers, 2016. Para o presente artigo, vamos nos utilizar da tradução francesa feita por Leili Anvar e também da tradução brasileira: Farid ud-Din Attar. A linguagem dos pássaros. 2 ed. São Paulo: Attar Editorial, 1991. 
original que está em verso e não em prosa. Trata-se de um "poema meditativo" com 4.724 dísticos (beyts). O grande tema da obra é o Amor do Bem-Amado. Um livro que encantou tantos místicos posteriores, como Rûmî (12071273), que sobre Attâr escreveu: "Attâr percorreu os sete vales do amor quando nós não chegamos senão na esquina".

Retomando místicos anteriores como Râbi'a e Hallaj, Attâr fala do "puro Amor", de uma busca que exige do sujeito um radical despojamento do ego. Para ir ao encontro de Simurgh (que é uma figura feminina ${ }^{7}$ ) há que se jogar no fogo de sua Presença e desaparecer. E esse horizonte do Amor está para além da clivagem tradicional entre crença e descrença, entre bem e mal. O Amor é um desafio paradoxal que exige do sujeito a ruptura das ilusões e do orgulho, de ultrapassagem de um ensimesmamento que é letal.

O livro de Attâr é precioso para ilustrar o processo que leva o buscador ao encontro do Amado (D 4517). Ele, porém, adverte no epílogo da obra sobre as condições para a leitura de seu texto poético: "Entra com amor neste diwan, entrega tua alma com abandono e adentra este palácio. Em semelhante hipódromo (espiritual), que jamais foi visível, e onde a alma não se mostra, se não entras com afeto não

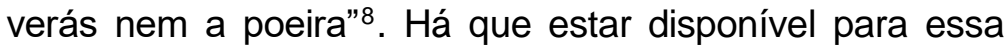
aventura: se o coração não está "mexido" o olhar não verá sequer uma "poeira se levantar" (D 4491).

Há um "perfume" no discurso de Attâr que escapa aos leitores que permanecem na superfície. O texto exige uma atenção particular, que é a do "caminho dos amantes". Só aqueles de "inteligência espiritual" podem acessar os sinais dos "segredos" que o livro contém. Diz Attâr: "O véu desta esposa do harém (divino) não será retirado do lugar de honra da Graça senão gradualmente" .

\section{Preparando o caminho}

Assim se revela o projeto fantástico da obra, que se inicia com um denso prólogo, antes da abordagem da epopeia dos pássaros em busca de Simurgh. Na abertura, a rica fórmula ritual bismillâh, que abre todas as suras do Corão, com exceção da sura IX: "bismillâh ar-rarhmân arrahîm" (Em nome de Deus, o Todo Misericórdia, o Misericordioso) ${ }^{10}$.

\footnotetext{
${ }^{7}$ Farîd od-dîn 'Attar. Le cantique des Oiseaux. Paris: Diane de Selliers, 2012, p. 31 (seguindo a explicação da tradutora, Leili Anvar).

8 Farid ud-Din Attar. A linguagem dos pássaros. 2 ed. São Paulo: Attar Editorial, 1991, p. 243 (epílogo).

9 Ibidem, p. 244

10 Em árabe, o nome al-Rahman, o Todo Misericórdia ou OmniMisericordioso, é um atributo que está reservado a Deus. Trata-se de um nome privativo de Deus.
} 
Nos primeiros dísticos do prólogo a colocação precisa do traço que marca o Mistério de Simurgh: sua dilatação (bast) e contração (qabz). Uma generosidade que faz clarear o dia e reter a obscuridade da noite ${ }^{11}$. E a noite tem um lugar singular nesta obra de Attâr, pois foi "em meio à noite" que ocorreu a primeira manifestação de Simurgh, e isto na China (D 736). Como assinalou Diane de Selliers em nota de rodapé, o fato desta manifestação ter ocorrido à noite revela algo de essencial, que é "tela de fundo da poesia mística persa". O buscador deve atravessar a noite, vencer as sombras interiores antes de acessar o Sol da Verdade ${ }^{12}$. E Attâr está aqui pensando também na célebre ascensão celeste e noturna do profeta Mohammad (miraj - D 269), que - levou da mesquita sagrada de Meca à mesquita de Jerusalém. Attâr fala deste "sagrado banquete" onde nem mesmo o anjo Gabriel veio admitido, pois "queimaria suas asas".

Os dísticos do prólogo são de uma beleza impar e abordam os grandes temas da mística sufi, como a presença viva do Mistério em todo o universo, sua irradiação mediante seus atributos; sua presença delicada, como um tesouro, ainda que "escondida". O tema da impenetrabilidade do Mistério recobre várias passagens do prólogo:

"Se a razão, por vezes, entrevê Tua presença ela jamais penetrará Tua essência" (D 77)

"Oh Tu que a razão aguarda em sua errância Tu que a inteligência deixou escapar em seu caminho" (D 80)

"É por meio de Tu que vejo o universo todo inteiro

E em todo o universo, nenhum sinal de Ti” (D 81)

E a linguagem é pobre, muito pobre, para expressar as riquezas deste Mistério:

"Como falar de Ti, quando eu, eu nada sei?" (D 93)

Mas o Mistério, apesar de escondido, manifesta aqui e ali os sinais de sua presença:

"Cada átomo do mundo abre um novo portal E cada um conduz a Ele por uma via nova” (D 96)

Mas é somente Ele que revela o caminho, jamais a razão. Para que a razão acesse os seus sinais ela necessita romper com o seu peso e obsessão. Se o buscador não processa essa kênose, se ele não deixa perder nada, não há nada a que buscar. Attâr insiste com o buscador: é necessário tornar-se nada, aniquilar-se, perder-se Nele para

11 Dístico 24, tomado da tradução francesa de Leili Anvar. Doravante, os dísticos citados aparecerão no texto com a abreviação $D$, seguida do número indicado.

12 Farîd od-dîn 'Attar. Le cantique des Oiseaux, p. 86-87 (nota 23). 
avançar no caminho: "Avance no Um, longe da dualidade. Unifica o teu coração e a tua qibla" (D 130).

Mais adiante, na reunião com os pássaros, a grande guia - a poupa - insiste sobre a importância de um coração polido para seguir adiante no caminho: um percurso que é longo e tortuoso, que requer empenho e tenacidade (D 729). Há que superar o egocentrismo (D 710) para inserir-se na "Via do Amado" (D 711). O Amado - Simurgh - está bem próximo de cada um, mas nem todos próximos dele (D 714). Seu nome está acima da possibilidade da língua (D 715) e seu esplendor embaçado por véus (D 716). Nem a alma mais pura consegue descrever seu Mistério (D 721). A graça de Simurgh reflete-se num espelho, e este espelho é o coração (D 1099). O desafio é encontrar seus sinais irradiados nas formas e cores do mundo (D 731) $)^{13}$.

O convite feito pela poupa aos pássaros, de ir em direção ao Mistério Maior, Simurgh, vem rebatido por eles, que recorrem com tantas desculpas para não avançar no caminho. O rouxinol argumenta que para ele basta o amor da rosa ( $D$ 765); o papagaio sugere que sua ambição é unicamente buscar a fonte da água "verdejante" - a fonte de Khezr - que é fonte de sabedoria (D 807); o pato está satisfeito com a superfície da água, ela é sua matriz, alegria e vida (D 855); a perdiz com o amor às pedras preciosas (D 891); o falcão com a companhia exitosa dos reis (D 951); a garça com a beleza da gota d'água na borda do mar (D 987). Outros dão suas desculpas, como o pardal, de corpo frágil, que receia a caminhada por não dispor de energias para tanto.

Diante das desculpas, a guia (poupa) argumenta de forma magistral. Numa de suas reflexões, assevera que pássaro algum é portador da constância necessária para seguir com tranquilidade o caminho, mas insiste na importância da abertura ao amor e sua dança (D 1082). A virtude da constância, argumenta, é coisa muito rara ( $D$ 1929). Se todos fossem puros, diz a poupa, Deus não teria enviado os profetas para sinalizar a riqueza do caminho. $\mathrm{E}$ sugere a oração: "Se do fundo de teu coração, manténs acesa a oração, terás um horizonte de paz, e isto lentamente, mas com certeza" (D 1929).

Para a poupa, as desculpas fornecidas eram "tolas". O importante era romper com os apegos e empreender a nobre jornada. Sua argumentação era clara: faz-se necessário preferir o Simurgh à própria vida, e isto envolve "combate" interior (jihad). Para a poupa, aquele a quem o amor abre os olhos caminha sempre, até o fim, arriscando a sua vida. $O$ amor não pode brotar num coração temeroso

\footnotetext{
${ }^{13}$ Há uma bela tradução do discurso da poupa aos pássaros: Farid udDin Attar. A conferência dos pássaros. São Paulo: Cultrix, 1993, p. 21 23.
} 
(D 1080). Só aquele que tem o coração polido, como um espelho, é capaz de mirada disponível para ver o Simorgh; só aquele que abre seu olhar ao amor é capaz de entrar "inteiramente na dança", colocando em questão a própria vida (D 1082). O amor, em verdade, "ama as coisas difíceis". É o amor que abre o acesso ao desnudamento (D 1185). Aqueles de fato amam, diz a poupa, não pensam apegadamente em suas vidas. Para os que sabem ver, 0 amor é a substância do universo inteiro (D 1182).

\section{A acolhida do chamado}

Ao final, mais de mil pássaros foram seduzidos a prosseguirem viagem. Todos partem arrebatados pela melodia da rola e do rouxinol (D 1661). A guia estava ali para ajudar os inquietos, para "fazer e desfazer os nós". Partem confiantes sob o olhar da poupa, a guia eleita por Salomão ${ }^{14}$. Os pássaros em sua jornada atravessam sete vales de dificuldades. Primeiramente, o vale do desejo ( $D$ 3257). Atravessá-lo é deixar-se inflamar pelo amor, como a borboleta pela chama (D 3266). Em seguida, o vale do amor (D 3358); do conhecimento (D 3502); da plenitude (D 3604); da unicidade (D 3720); da perplexidade (D 3827), para então concluir com o vale da aniquilação (D 3968).

É interessante verificar que o vale que precede a imersão no seio da Simorgh é aquele da aniquilação ou da pobreza (faqr). Isto vem carregado de profundo simbolismo. Numa das histórias que acompanham a descrição desse vale, a bela narrativa das farfalas ou borboletas noturnas (papillons) que se disponibilizam a ir ao encontro da chama. Das três borboletas que se dispuseram a fazer a experiência, só a terceira viveu de fato o encontro. As duas primeiras apenas captaram "alguma coisa do mistério" (D 4020). A terceira, que conseguiu a façanha, foi aquela que se deixou inebriar pelo amor: que foi dançando ao encontro da chama, e abraça sem temor o fogo (D 4024). Na expressão da sábia borboleta, só mesmo a última, só ela, e nenhuma outra, captou o segredo (D 4027).

\section{No calor da Presença}

De todos os mil pássaros que empreenderam a jornada, apenas 30 chegaram ao destino. Os outros ficaram pelo caminho. Não poucos se perderam nas mais altas montanhas, vencidos pela sede e tomados pela dor ( $D$ 4170); alguns foram queimados pelos raios solares, com os corações calcinados (D 4171); outros foram devorados por felinos vorazes e violentos (D 4172); outros acabaram cedendo a prazeres distintos (D 4178) e aqueles que foram rendidos pelo calor calcinante dos desertos (D 4174).

${ }^{14}$ A poupa vem mencionada no livro do Corão: XXVII,20. 
Poucos foram aqueles que conseguiram aceder ao limiar (D 4167). Foram trinta os restantes, e estes mostravam-se "perplexos, cansados, desanimados, sem penas e asas" (D 4181), com os corpos esgotados e os corações partidos. Estavam como átomos pasmos e estupefatos. Estes chegaram ao portal do Misericordioso, sendo recebidos pelo camarista da soberana corte (D 4191). A perceber a chegada dos pássaros, o guardião indagou sobre a caminhada empreendida, mas reagiu ao fato dos pássaros manifestarem mais gemidos e lamentações do que a alegria de estar diante de Simurgh. Estranhou o fato de estarem ali, no portal do Amado, tão prostrados e esvaziados (D 4193). O guardião indaga por seus nomes e por sua pertença.

Os pássaros respondem em uníssono que vieram de longe, como errantes em busca do aconchego da Misericórdia. Lamentam sobre as perdas no caminho, o cansaço vivido e as dores do coração. $E$ recordam que eram antes milhares e agora apenas trinta (D 4198-4199). Tudo realizado com a finalidade de encontrar a "Presença junto à Sua Majestade" (D 4200). E que diante de tantas penas e sofrimentos, pudessem então ser acolhidos com um olhar de graça (D 4201).

O guardião da corte de Simurgh reage aos pássaros: "O que trazeis além desses gemidos $\mathrm{e}$ lamentações. Regressai ao sítio de onde viestes, ó pobres loucos!" ( D 4205). Pegos de surpresa, os pássaros caem em desespero, a ponto de parecerem mortos (D 4206). Não podiam sequer imaginar que seriam rejeitados por Simurgh. Foi quando então, tomados pelo êxtase, como aniquilados, recordaram a narrativa das borboletas que não temem a flama: "Eis nossas almas. Que o fogo as devore!" (D 42154216). Agora, tomados pelo calor do fogo e libertos do peso das reclamações ou dos desejos, são preenchidos pela dinâmica da Graça (D 4225). Assim, no novo clima, o guardião enfim abre a porta e vai desvelando os véus, descerrando as cem cortinas que impediam a mirada. Faculta-se, então, o acesso à Luz Suprema (D 4226-4227).

Só nesta etapa final, depois de longas peregrinações, é que os pássaros se dão conta do Mistério, diante da luz das luzes: Quando se viram totalmente em paz, purificados de tudo, desapegados e livres, perceberam que a Simurgh se achava ali na companhia deles e que algo novo começava ali para eles naquela Presença (D 4258). Tudo o que haviam feito anteriormente se apagou, e ao se olharem mutuamente perceberam a presença do reflexo da Simorgh, a sua Face Soberana. Assim captaram, finalmente, que a Simorgh era o sî morgh ${ }^{15}$. No reflexo do rosto de cada um, os trinta pássaros do mundo exterior contemplaram o rosto da Simurgh do mundo interior. E a

${ }^{15}$ Literalmente "trinta pássaros". 
história se conclui de forma extraordinária, com os pássaros sendo aniquilados no "Si" de Simurgh: "Logo depois perderam-se os pássaros para sempre no Simurgh - a sombra perdeu-se no sol, e isso é tudo".

\section{Conclusão}

A linguagem dos pássaros é antes de tudo uma "epopeia espiritual". Trata do caminho que leva o buscador ao horizonte do Amado. Attar adverte ao leitor sobre a importância de ler o livro com uma outra lógica: a lógica do coração. Aqueles que não entram com esse espírito acabam naufragando nos seus versos. Os que se sintonizam com o espírito indicado, ao contrário, são capazes de captar sua música e penetrar em seus segredos mais profundos. Trata-se de um "poema meditativo" que a cada instante irradia dons incalculáveis. É o que indica Attar no epílogo de sua obra. Daí a importância de retomar sua leitura em momentos diversificados (D 4507). Ele sublinha a singular virtude que acompanha o livro, que a cada passo desperta nova generosidade (D 4906). É uma obra grandiosa, que como outras da mística universal, aponta a trajetória indicada para o acesso ao Mistério Incognoscível.

\section{Referências Bibliográficas}

ATTAR, Farîd od-dîn. Le cantique des oiseaux. Paris: Diane de Selliers, 2012.

ATTAR, Farîd od-dîn. Le cantique des oiseaux. Paris: Diane de Selliers, 2016 (llustré par la peinture en islam d'orient).

ATTAR, Farid ud-Din. A linguagem dos pássaros. 2 ed. São Paulo: Attar Editorial, 1991.

ATTAR, Farîd ud-Din. Le langage des oiseaux. Paris: Albin Michel, 1996.

CARRIÈRE, Jean-Claude. La conférence des oiseaux. Récit théatral. Paris: Albin Michel, 2008.

RITTER, Hellmut. I/ mare dell'anima. Uomo, mondo e Dio in Farîduddîn 'Attâr. Milano: Ariele, 2004.

SACCONE, Carlo. II maestro sufi e la bella cristiana. Roma: Carocci, 2005. 